\title{
Pilot Scale Production of Manganese Ferroalloys Using Heat-Treated Mn-Nodules
}

\author{
MERETE TANGSTAD, ${ }^{1,4}$ ELI RINGDALEN, ${ }^{2}$ EDMUNDO MANILLA, ${ }^{3}$ \\ and DANIEL DAVILA ${ }^{3}$
}

1.-Norwegian University of Science and Technology (NTNU), 7491 Trondheim, Norway. 2.-SINTEF, Trondheim, Norway. 3.-Autlan, Ejido Tamos, C.P. 92018, Veracruz, Mexico. 4.-e-mail: merete. tangstad@ntnu.no

\begin{abstract}
Pilot-scale experiments are one way to investigate the process patterns and the reaction mechanisms of processes and raw materials. To understand a process fully, both theoretical considerations as well as small-scale investigations are needed; nevertheless, the complex patterns of chemical reactions and physical phenomena can best be studied in pilot-scale investigations. After studying the chemical and mineralogical properties, the strength and the melting behavior of Mn-nodules, presented in a previous paper, the process behavior of the ore is studied in a pilot scale experiment. The industrial process is simulated in a topand bottom-electrode furnace operated at about $150 \mathrm{~kW}$. The high-strength, low-melting Mn-nodules produced by Autlan were the main raw material mixed with Comilog ore and some lime. It was shown that the Mn-nodules behave in principle like other commercial Mn-raw materials. The ore will at the border of the high-temperature area produce a liquid in coexistence with a $\mathrm{MnO}$ phase. As the ore is reaching the cokebed zone, the ore is already fully reduced. The ore will not be reduced much more in the cokebed area. The slag will be tapped at the composition close to the liquidus composition, as observed for other Mn-raw materials, and thus, also follow the well-known rule of lower $\mathrm{MnO}$ content in the slag with higher basicity.
\end{abstract}

\section{INTRODUCTION}

Manganese ferroalloys are a large group of ferroalloys containing mainly manganese but also some iron and a smaller amount of carbon. Although other elements may be present, such as silicon in silicomanganese or nitrogen in nitrided ferromanganese, this article will be restricted to one of the main $\mathrm{Mn}$ alloys where the sum of $\mathrm{Mn}+\mathrm{Fe}+\mathrm{C}$ is more than $99 \%$, and the last percent is trace elements. This alloy is often referred to as FeMn, which will also be done in this article. FeMn can be produced in submerged arc furnaces or in blast furnaces. The submerged arc furnace gives a more flexible way of production as both manganese ferroalloys with and without silicon can be produced. As a higher temperature is needed to produce manganese alloys with silicon, blast furnaces cannot be used to produce this product. This means that the major part of the FeMn production in the word today is produced in submerged arc furnaces (SAFs).
The main raw materials in the production process are $\mathrm{Mn}$-sources to provide for the $\mathrm{Mn}$ and iron, fluxes; to adjust the slag chemistry and carbon; to remove oxygen. The Mn-sources can typically be lumpy ore, like the commercial Comilog ore, Groote Eylandt ore, and Mamatwan and Assmang ores, to mention a few. To adjust the sizing or the chemical composition, the Mn-source can also be heat-treated materials like sinter, pellets, or nodules. This group will also include Mn-containing recycled materials, both from production or as a by-product from other processes. As there is an increased focus on zerowaste production, the latter is becoming more important for all producers. Fluxes are typically basic oxides like limestone $\left(\mathrm{CaCO}_{3}\right)$, burned limestone $(\mathrm{CaO})$, and dolomite $\left[(\mathrm{Ca}, \mathrm{Mg}) \mathrm{CO}_{3}\right]$. When these basic materials are added, it will first force more manganese over to the metal phase; it will, however, also affect the physical properties of the slag, like viscosity and resistivity. Finally, the carbon materials are also a vital part of the raw 
material mixture. Typically metallurgical coke is used, but also coal, char, charcoal, and anthracite can be used. The main property of the carbon is its ability to remove oxygen from the ore; however, equally important may be the electrical properties of the carbon material in the cokebed. The main part of the electrical energy is produced by ohmic heating of the carbon materials in the high-temperature zone.

The furnace may be divided in two main zones: the prereduction zone and the cokebed zone. The prereduction zone is the low-temperature zone where all the higher manganese oxides is reduced to $\mathrm{MnO}$, the carbonates are decomposed to basic oxides of $\mathrm{CaO}$ and $\mathrm{MgO}$, and water is evaporated. The iron oxides may also be reduced down to metallic iron. This will happen in the temperature area from where the raw materials are entering the furnace, which could typically be from $100^{\circ} \mathrm{C}$ to $600^{\circ} \mathrm{C}$ and up to where the ore starts to melt between $1200^{\circ} \mathrm{C}$ and $1400^{\circ} \mathrm{C}$. The raw material will now be a mixture of the oxides of $\mathrm{MnO}-\mathrm{CaO}-\mathrm{MgO}-$ $\mathrm{SiO}_{2}-\mathrm{Al}_{2} \mathrm{O}_{3}$, with metallic iron being distributed in the oxide phase and carbon particles. The oxide mixture will start to melt as it enters the cokebed zone. The main reaction in the cokebed zone will be the reduction of $\mathrm{MnO}$ to $\mathrm{Mn}$, and the melted oxide phase, the slag, will be depleted in MnO. For many operations, the $\mathrm{MnO}$ content will end up close to the liquidus composition, and the slag will be tapped together with the metal or in a separate tap-hole.

Autlan, a large FeMn producer in Mexico, has a deposit of manganese ore in the state of Hidalgo, Mexico. The ore contains manganese carbonate and is processed into manganese nodules in a rotary kiln, where thermal conversion is carried out. The chemical composition and properties of typical nodules was published previously. ${ }^{1}$ The chemical analysis is shown in Table I and shows that the $\mathrm{Mn} / \mathrm{Fe}$ ratio is about 5 . The manganese is present as $\mathrm{MnO}$, with the amount of higher manganese oxides (represented by the content of $\mathrm{MnO}_{2}$ ) at zero. The total basicity, given by the ratio $(\mathrm{CaO}+\mathrm{MgO}) /$ $\left(\mathrm{SiO}_{2}+\mathrm{Al}_{2} \mathrm{O}_{3}\right)$, is close to 1 , which means that fluxes are not necessary.

As for most heat-treated materials, the ore contained a $\mathrm{MnO}$ phase in coexistence with a tephroite phase $\left((\mathrm{Mn}, \mathrm{Ca})_{2} \mathrm{SiO}_{4}\right)$. The analysis of the $\mathrm{MnO}$ phase is $70-80 \% \mathrm{MnO}$ with about $20 \% \mathrm{FeO}$ and $5-$
$10 \% \mathrm{MgO}$ dissolved. The main matrix phase is the tephroite phase with about $30 \% \mathrm{SiO}_{2}$, where $10 \% \mathrm{MgO}$ and $20-30 \% \mathrm{CaO}$ is dissolved in $30 \% \mathrm{MnO}$. A minor phase is galaxite $\left((\mathrm{Mn}, \mathrm{Mg}) \mathrm{Al}_{2} \mathrm{O}_{4}\right)$ with $50 \% \mathrm{Al}_{2} \mathrm{O}_{3}$ and a solution of $20-25 \% \mathrm{MnO}, 10 \% \mathrm{MgO}$, and $12 \% \mathrm{FeO}$. The nodules also showed a high thermal strength, where more than $95 \%$ of the particles are kept at original size during heating. This is much better than many commercial ores where typically only $40-70 \%$ of the ore contain their original size during heating and prereduction. It can also be mentioned that the nodules start to melt in the temperature area 1200 $1300^{\circ} \mathrm{C}$, which is lower than most other Mn-sources. ${ }^{1}$ These types of investigation are imperative when studying different types of raw materials. Depending on their properties, raw materials may give different reaction mechanisms in a submerged arc furnace. To learn more about the reaction mechanisms for this raw material in an SAF, a pilot-scale furnace experiment was carried out. This article will describe the operation of the furnace, but more importantly, it will describe the reduction of the $\mathrm{MnO}$ and the reminding slag composition in the high-temperature zone.

\section{EXPERIMENTAL PROCEDURE AND OPERATION}

The experiments were performed in the 440-kVA pilot furnace at SINTEF/NTNU. A picture of the furnace is shown in Fig. 1. The experiments were run with a top and bottom electrode. The aim for the operation was a fixed electrode tip position $20 \mathrm{~cm}$ above the furnace bottom and a stable load of $150 \mathrm{~kW}$. The first tapping was done after $300 \mathrm{kWh}$, and the following tapping at each $80 \mathrm{kWh}$. During the experiment, the electrical parameters were logged automatically as a part of the furnace control system.

The furnace is excavated by an excavation technique developed by B. Heiland at NTNU/Glencore. The furnace is shut off $40 \mathrm{kWh}$ after the last tapping. It is then cooled for approximately $72 \mathrm{~h}$ before epoxy is poured into the furnace. After another $48 \mathrm{~h}$, the epoxy has hardened and the electrode is cut. The furnace is taken away in one piece, and a cross-section plate through the center of the furnace is cut. The distribution of the different zones in the furnace can then be studied. Samples are taken out at different positions to be studied in

Table I. Raw material analysis

\begin{tabular}{|c|c|c|c|c|c|c|c|c|c|}
\hline & $\% \mathbf{M n}_{\text {TOT }}$ & $\% \mathbf{F e}_{\text {тот }}$ & $\% \mathrm{SiO}_{2}$ & $\% \mathrm{Al}_{2} \mathbf{O}_{3}$ & $\% \mathrm{CaO}$ & $\% \mathrm{MgO}$ & $\%$ Fix C & $\% \mathrm{H}_{2} \mathrm{O}$ & $\mathbf{k g}$ \\
\hline Mn nodules & 37.3 & 8.1 & 14.5 & 3.9 & 14 & 6.6 & & 0.9 & 24.2 \\
\hline Comilog MMA & 47.5 & 3.8 & 5.52 & 6.79 & 0.2 & 0.3 & & 2.5 & 6.2 \\
\hline Limestone & & 0.2 & 0.4 & 0.5 & 54 & & & 0 & 1.3 \\
\hline Coke & & 1.0 & 11.26 & 0.25 & 0.24 & & 85 & $0^{\mathrm{a}}$ & 4.2 \\
\hline
\end{tabular}

${ }^{\text {aAfter drying. }}$ 
the EPMA (Electron ProbeMicroAnalyzer) to study the slag composition. Hence, the degree of reduction versus position can be evaluated.

A charge mixture, similar to the mixture used in industrial operation at Autlan, was used in the experiment. The analyses of the raw materials and the mixture are shown in Table I. The charge consisted of Mn-nodules, Comilog MMA ore, limestone, and coke. The charge mixture was calculated based on the assumptions of producing an alloy with $75 \% \mathrm{Mn}$; a slag with $20 \% \mathrm{Mn}$ and overall basicity, $\left(\mathrm{MgO}+\mathrm{CaO} / \mathrm{Al}_{2} \mathrm{O}_{3}+\mathrm{SiO}_{2}\right)$, of 1 ; and a slag/alloy ratio of 1.15 . The Comilog ore has a higher $\mathrm{Mn} / \mathrm{Fe}$ ratio than the Autlan nodules, and it is added to obtain a higher Mn content in the metal. As Comilog ore is an acid ore, some lime must be added to obtain the given basicity.

\section{Furnace Operation}

In this type of experiment the electrode position is kept as constant as possible. The total load on the furnace and the resistance are shown in Fig. 2. In an electrical control system for operating a furnace, there are only two independent variables, and then the rest is fixed. In this type of experiment, it is aimed for $150 \mathrm{~kW}$ and a height between the electrode tip position and the bottom lining of $20 \mathrm{~cm}$. Then the resistance, the electrical current, and the voltage is fixed. Figure 2 shows the load and the resistance during the experiment. The power was kept in the area of $150 \mathrm{~kW}$, but in the first part of the experiment, it was up to $200 \mathrm{~kW}$. The furnace was tapped every $80 \mathrm{kWh}$. The resistance increases during the taps as slag is drained from the cokebed. As will be discussed later in this article, the furnace was unintentionally operated undercoked. With a fixed electrode position and an undercoked situation, that is a high slag/coke ratio in the cokebed, this led to very high resistances during tapping. Hence, the voltage and current was out of range on occasions, and hence, the electrode positions were adjusted accordingly.

Table II shows the metal and slag analyses from tap 1 to 10 . The metal has an average of $74.4 \% \mathrm{Mn}$ and is close to the aimed value. The $\mathrm{MnO}$ in the slag is a bit higher compared with the aimed value, $30 \%$ compared with $26 \%$. This is very typical in this furnace as the reduction paths are short. Yet, as the slag contains some metallic $\mathrm{Mn}-\mathrm{Fe}$ solution, as
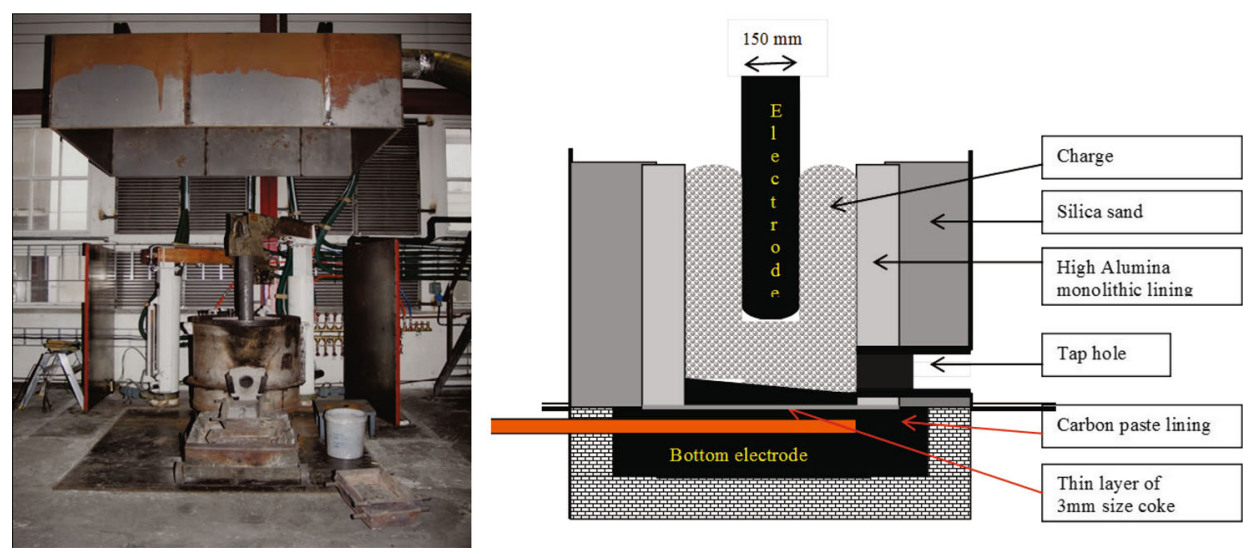

Fig. 1. Picture and sketch of pilot-scale furnace.
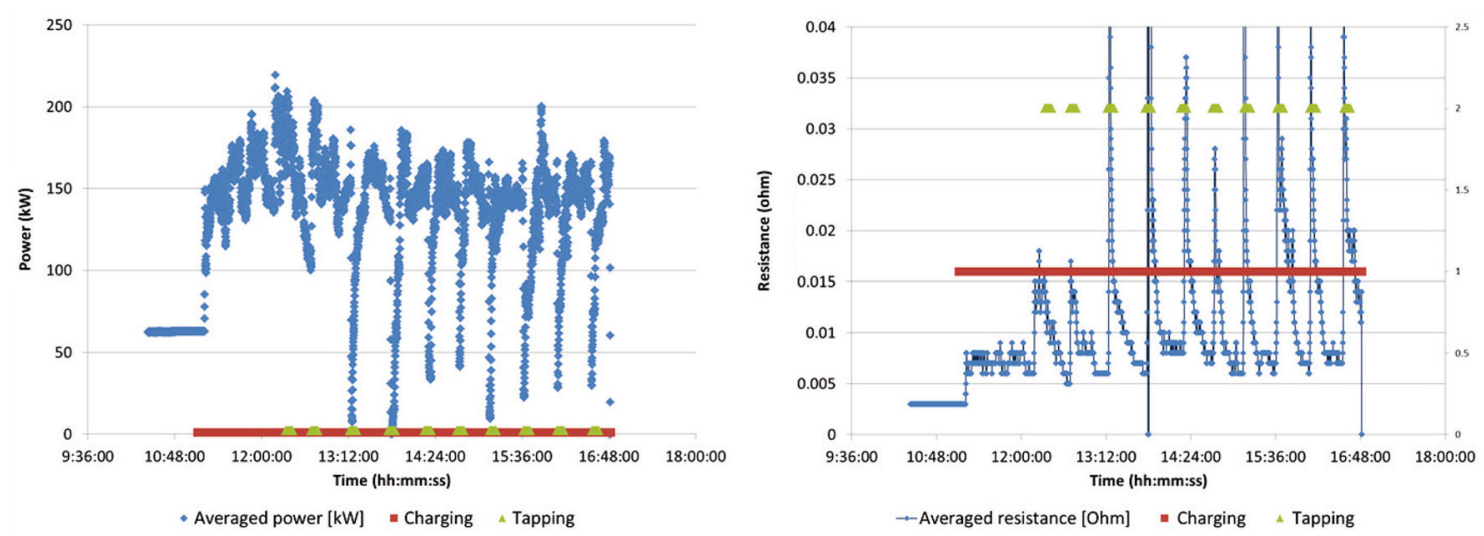

Fig. 2. Power and resistance during experiment. 
observed in the Fe content, the real $\mathrm{MnO}$ content may be a couple of percentage lower than given in Table I. The basicity is close to the aimed values, which shows that the analyses are in good agreement with the measured analyses.

The masses of the metal and slag taps are shown in Table III. The aimed goal for the slag/metal ratio was 1.15 . The attained slag/metal ratio is close to 2 , and this can be explained by a high metal content in the slag. By assuming $20 \%$ metal in the slag, the corrected slag/metal ratio will be close to the theoretical 1.15. This is a very high metal content in the slag, which could be a result of a slightly higher $\mathrm{MnO}$ content in the slag again because of the undercoking. When undercoking occurs, this could lead to a solid $\mathrm{MnO}$ phase in the slag and, hence, to a more viscous slag. This has been observed in other pilot-scale experiments that have been dramatically undercoked. $^{2}$

\section{Furnace Interior and Slag Development in Furnace}

Figure 3 shows the interior of the furnace after shutdown, cooling, casting with epoxy, and cutting. As typically found in these excavations, the furnace may be divided in two main zones: one pre-reduction zone where the charge behaves like solid (zone II) and the high-temperature zone or the cokebed zone (zone III, IV, and V). As for industrial furnaces, the high-temperature zone, which is the cokebed zone, can be too small or too big if the charge is

Table II. Metal and slag analyses

\begin{tabular}{|c|c|c|c|c|c|c|c|c|c|c|c|}
\hline Tap no. & $\mathbf{1}$ & 2 & 3 & 4 & 5 & 6 & 7 & 8 & 9 & 10 & Average \\
\hline Mn (wt.\%) & 75.3 & 71.9 & 74.4 & 74.3 & 74 & 73.9 & 74.7 & 75.1 & 74.7 & 75.4 & 74.4 \\
\hline $\mathrm{Fe}($ wt. $\%)$ & 16.4 & 21.3 & 18.4 & 18.7 & 19.2 & 19.3 & 18 & 17.8 & 18.1 & 17.2 & 18.4 \\
\hline Si (wt.\%) & 0.73 & 0.1 & 0.07 & 0.13 & 0.07 & 0.06 & 0.07 & 0.08 & 0.11 & 0.1 & 0.16 \\
\hline $\mathrm{P}$ (wt.\%) & 0.28 & 0.39 & 0.31 & 0.3 & 0.28 & 0.31 & 0.25 & 0.26 & 0.24 & 0.22 & 0.28 \\
\hline $\mathrm{Ti}$ (wt.\%) & 0.05 & 0.01 & 0.01 & 0.01 & 0.01 & 0.01 & 0.01 & 0.01 & 0.01 & 0.01 & 0.01 \\
\hline \multirow[t]{2}{*}{$\mathrm{C}$ (wt.\%) } & 6.84 & 6.8 & 7.06 & 6.83 & 6.89 & 6.97 & 6.98 & 7.05 & 7.04 & 6.9 & 6.9 \\
\hline & 99.6 & 100.5 & 100.2 & 100.3 & 100.5 & 100.6 & 100.0 & 100.3 & 100.2 & 99.8 & \\
\hline Tap no. & 1 & 2 & 3 & 4 & 5 & 6 & 7 & 8 & 9 & 10 & Average \\
\hline $\mathrm{MnO}(\mathrm{wt} . \%)$ & 22.1 & 32.8 & 31.8 & 32.1 & 35.8 & 32.6 & 31.2 & 27.2 & 32.9 & 28.7 & 30.7 \\
\hline $\mathrm{SiO}_{2}$ (wt.\%) & 27.6 & 24.8 & 24.3 & 25.4 & 23.6 & 25 & 24.7 & 26 & 24.1 & 25.5 & 25.1 \\
\hline $\mathrm{CaO}$ (wt.\%) & 27.2 & 26.4 & 26.1 & 26.1 & 24.4 & 27.2 & 26.8 & 28.5 & 25.8 & 27.1 & 26.6 \\
\hline $\mathrm{MgO}$ (wt.\%) & 10.5 & 8.3 & 9.7 & 8.6 & 8.6 & 7.7 & 9.8 & 10.6 & 9.8 & 10.9 & 9.5 \\
\hline $\mathrm{AI}_{2} \mathrm{O}_{3}$ (wt.\%) & 12.1 & 7.4 & 7.4 & 7.2 & 6.8 & 7.3 & 7 & 7.3 & 6.7 & 7 & 7.6 \\
\hline $\mathrm{K}_{2} \mathrm{O}$ (wt.\%) & 0.18 & 0.15 & 0.13 & 0.24 & 0.29 & 0.24 & 0.2 & 0.21 & 0.29 & 0.28 & 0.2 \\
\hline $\mathrm{BaO}$ (wt.\%) & 0.22 & 0.22 & 0.22 & 0.22 & 0.23 & 0.23 & 0.21 & 0.21 & 0.22 & 0.22 & 0.2 \\
\hline \multirow[t]{2}{*}{$\mathrm{Fe}($ wt.\%) } & 0.4 & 0.2 & 0.6 & 0.4 & 0.7 & 0.1 & 0.4 & 0.2 & 0.5 & 0.7 & 0.4 \\
\hline & 99.9 & 100.1 & 99.7 & 99.9 & 99.7 & 100.3 & 99.9 & 100.0 & 99.8 & 99.7 & \\
\hline Basicity & 0.95 & 1.08 & 1.13 & 1.06 & 1.09 & 1.08 & 1.15 & 1.17 & 116 & 117 & 1.10 \\
\hline
\end{tabular}

Table III. Metal and slag taps (kg)

\begin{tabular}{|c|c|c|c|c|c|c|}
\hline & Metal & Slag & $\underline{\mathbf{s} / \mathbf{m}}$ & Metal (cor.) & Slag (cor.) & s/m (cor.) \\
\hline Tap 1 & 23.8 & 37.7 & 1.6 & 31.4 & 30.2 & 0.96 \\
\hline Tap 2 & 9.6 & 26.3 & 2.8 & 14.8 & 21.0 & 1.42 \\
\hline Tap 3 & 22.2 & 38.9 & 1.8 & 30.0 & 31.1 & 1.04 \\
\hline Tap 4 & 16.5 & 32.6 & 2.0 & 23.0 & 26.1 & 1.14 \\
\hline Tap 5 & 10.7 & 33.6 & 3.1 & 17.4 & 26.9 & 1.54 \\
\hline Tap 6 & 11.8 & 25.0 & 2.1 & 16.8 & 20.0 & 1.19 \\
\hline Tap 7 & 13.1 & 27.2 & 2.1 & 18.5 & 21.8 & 1.18 \\
\hline Tap 8 & 14.8 & 26.0 & 1.8 & 20.0 & 20.8 & 1.04 \\
\hline Tap 9 & 13.6 & 29.6 & 2.2 & 19.5 & 23.7 & 1.22 \\
\hline Tap 10 & 15.6 & 30.0 & 1.9 & 21.6 & 24.0 & 1.11 \\
\hline Total & 151.6 & 306.9 & 2.0 & 213.0 & 245.6 & 1.15 \\
\hline
\end{tabular}

The corrected values are under an assumption of $20 \%$ metal in the slag. 


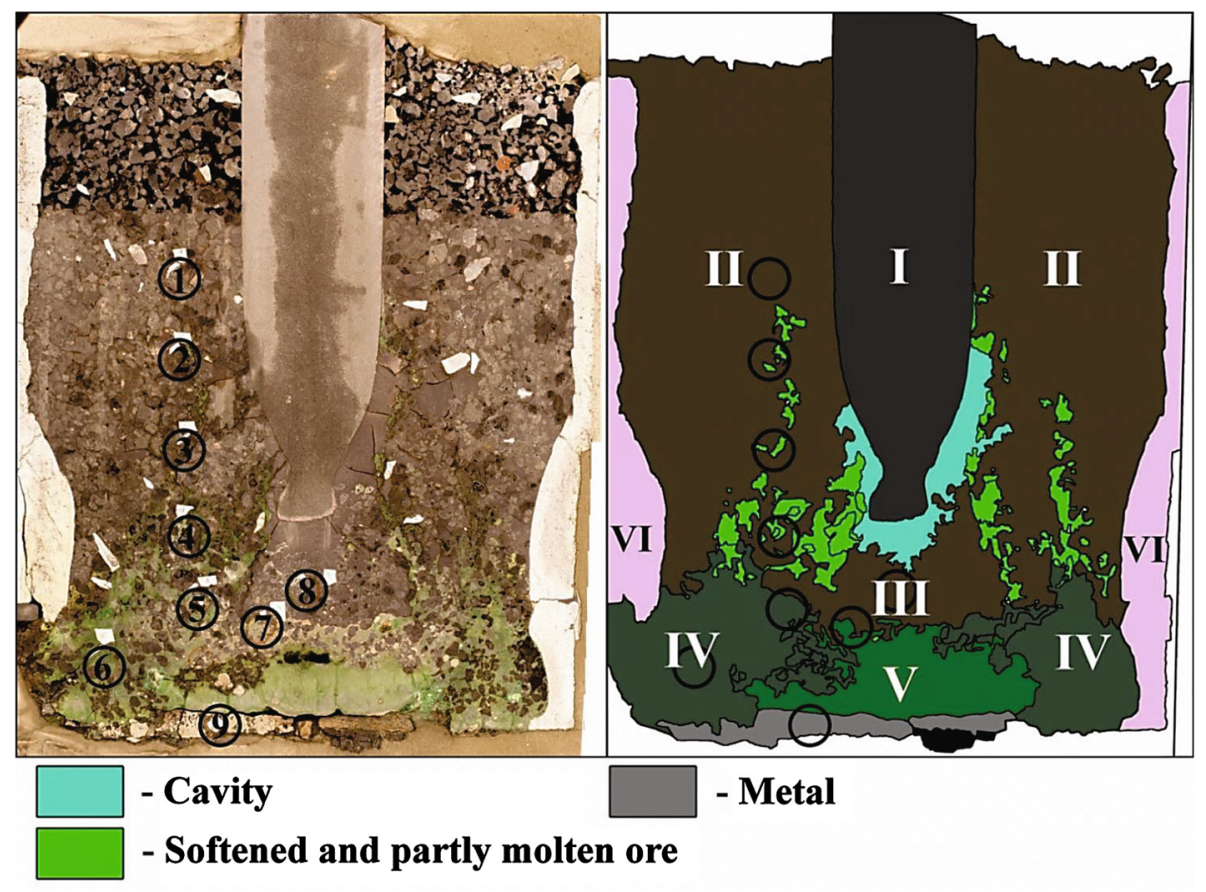

Fig. 3. The image of the furnace cross section is on the left side. The schematic illustration of the plate with corresponding zones is shown on the right side. The cavity, metal, and softened ore particles are marked with color. The other zones are marked as follows: I-electrode, II-charge materials, III-coke-bed zone, IV-mixture of slag with coke, V-slag layer, VI-lining material. Position of the core drills is marked with the numbers from 1 to 9 .

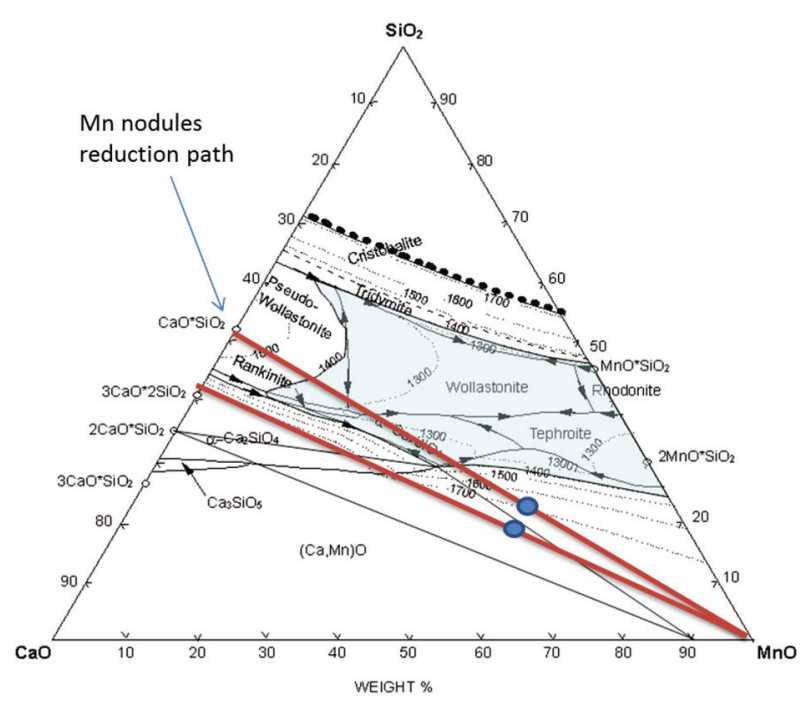

Fig. 4. $\mathrm{MnO}-\mathrm{CaO}-\mathrm{SiO}_{2}$ phase diagram where the reduction path of Mn-nodules are indicated. For the $\mathrm{Mn}$ nodules, $\mathrm{MgO}$ is added to $\mathrm{CaO}$ and $\mathrm{Al}_{2} \mathrm{O}_{3}$ to $\mathrm{SiO}_{2}$. Two reduction lines are given for $B=1$ and $B=1.4$ (after Ref. 5).

undercoked or overcoked respectively. In this experiment, a typical example of a cokebed with too little coke is observed. One will then see areas with more or less pure slag, zone V. As the slag has a tendency to collect under the electrode, and coke is in the upper part of the cokebed, the electrical currents are forced through the sides of the electrode, giving the electrode an uneven shape. Figure 3 also shows the positions of samples investigated, marked from 1 to 9.

Typically, in other experiments, dolomite or limestone is not found in the high-temperature area. Yet, in Fig. 3, one can see the dolomite all the way to the tap hole. This could be a result of the undercooking and more fluent materials in the hightemperature area. It could also be because the Mnnodules melt at very low temperatures, leading to a very low temperature in the cokebed. It has been observed previously that low-melting materials give a lower temperature in the melting zone. ${ }^{3,4}$

Before the analyses of samples shown in Fig. 3 (marked 1-9) is studied, the theoretical reduction path as shown in Fig. 4 is discussed. First, previous characterization shows that Mn-nodules consist of $(\mathrm{Mn}, \mathrm{Mg}, \mathrm{Fe}) \mathrm{O}, \quad(\mathrm{Mn}, \mathrm{Ca}, \mathrm{Mg})_{2} \mathrm{SiO}_{4}, \quad$ and small amounts of $(\mathrm{Mn}, \mathrm{Mg}, \mathrm{Fe}) \mathrm{Al}_{2} \mathrm{O}_{4}$. This is probably close to the phases given by thermodynamic equilibrium at the high production temperature. As the $\mathrm{Mn}$ nodules will continue to heat up in the pilot furnace above $1300-1400^{\circ} \mathrm{C}$, it will consist of a solid $\mathrm{MnO}$ phase and a liquid slag. (As observed in previous tests, this could also happen at lower temperatures, as Mn-nodules melt at low temperatures. ${ }^{1}$ ) The tephroite phase $(\mathrm{Mn}, \mathrm{Ca}, \mathrm{Mg})_{2} \mathrm{SiO}_{4}$ may also be present, which is especially dependent on the basicity. There is $\mathrm{Al}_{2} \mathrm{O}_{3}$ in the system, and hence, galaxite $(\mathrm{Mn}, \mathrm{Mg}) \mathrm{Al}_{2} \mathrm{O}_{4}$ may also be present at a high temperature. As the reduction of $\mathrm{MnO}$ starts to 


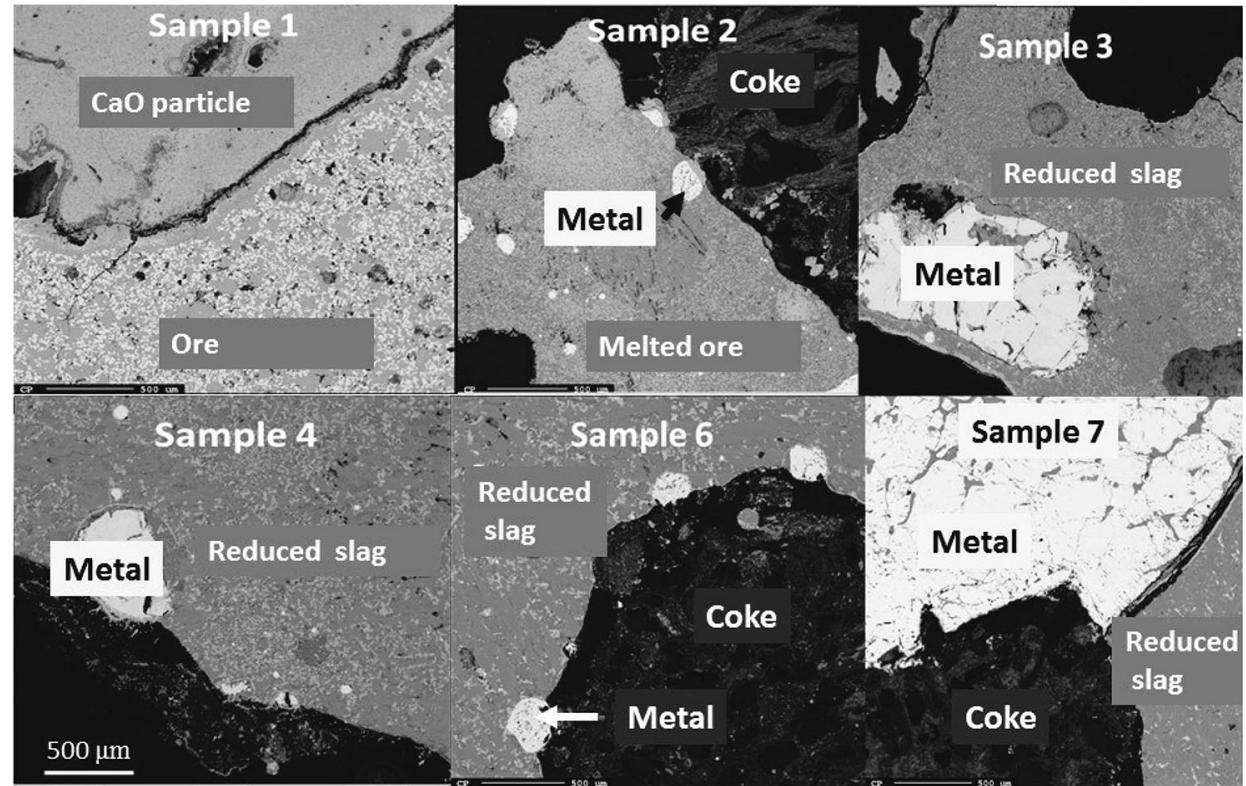

Fig. 5. Overview of slag at different positions in the furnace (all at same magnification).

occur, $\mathrm{MnO}+\mathrm{C}=\mathrm{Mn}+\mathrm{CO}$, the slag will be depleted in $\mathrm{MnO}$ and the slag composition moves along the reduction path line. The solid $\mathrm{MnO}$ phase will dissolve until no solid $\mathrm{MnO}$ phase is present. This was seen at the small-scale induction furnace test described in the previous paper. ${ }^{1}$

Samples from both the prereduction area (sample 1-3) and from the cokebed were studied (samples 49) at the EPMA. Micrographs from some samples are shown in Fig. 5. At sample 1, well above the high-temperature zone, the phases given by the phase diagram are observed. This is especially a solid $\mathrm{MnO}$ phase containing about $15 \% \mathrm{FeO}$. Sample 2 should also be above the cokebed where the reduction has not yet started. Nevertheless, in the picture, one can see partly reduced slag to metal. Here, the large metal pearls contain more than $80 \%$ $\mathrm{Mn}$ and the solid $\mathrm{MnO}$ phase less than 6\% FeO. This is surprising as this sample is not from the hightemperature zone. Yet, there has been slag boiling into this area, and the results could be from slag boiling from the high-temperature area. Another possible explanation is that as the nodules have a very low melting point, these reactions may start a bit above the cokebed. Sample 3, 4, 6, and 7 all show the same structure of the slag. Now the solid $\mathrm{MnO}$ particles are more or less dissolved. Nonetheless, because the slag takes some time to cool in this furnace, some solid $\mathrm{MnO}$ phase precipitates during cooling. Yet, this $\mathrm{MnO}$ phase is not as spherical as the original $\mathrm{MnO}$ phase is.

The microprobe results follow previous investigations in that the solid $\mathrm{MnO}$ will dissolve in the liquid phase and the tapped slag will have $\mathrm{MnO}$ content close to the liquidus composition. ${ }^{6}$ In Fig. 6 , the

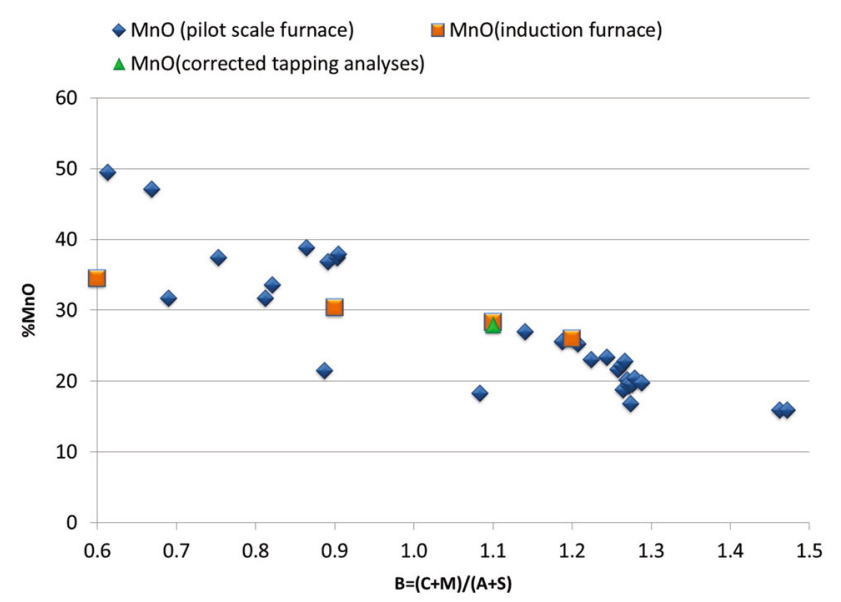

Fig. 6. $\mathrm{MnO}$ in the matrix phase (equal to the liquid phase and the liquidus composition) as a function of basicity in the samples (The results from the induction furnace experiments are published in Ref. 1).

$\mathrm{MnO}$ content in the liquid phase is given as a function of basicity for the liquid phase in the samples. As seen previously, and as seen in the phase diagram, the $\mathrm{MnO}$ content will decrease with increasing basicity. For a basicity of 1.10 , the $\mathrm{MnO}$ content will be about $25 \% \mathrm{MnO}$. Nevertheless, as the samples have been exposed to a very slow cooling, these analyses may be a bit inaccurate. The overall $\mathrm{MnO}$ content and its dependency on basicity is, however, in good agreement with the results from the liquidus composition analyzed in the induction furnace experiment published in Ref. 1 as well as with the average tapping analyses. 


\section{CONCLUSION}

A pilot-scale experiment was done with $\mathrm{Mn}$ nodules, Comilog ore, and limestone. The $\mathrm{MnO}$ content was about $28 \%$ with a basicity of 1.1 . The main observation from the pilot experiment is in general that the Mn-nodule follows the reduction trend as previous seen in pilot- and industrial-scale furnaces for other ores. The furnace interior after the experiment with $\mathrm{Mn}$-nodules is similar to the furnace interior after $\mathrm{HC}$ FeMn experiments with other Mn sources as, e.g., Comilog ore.

The $\mathrm{MnO}$ reduction occurs mainly on the top of the cokebed (high-temperature area). The Mn nodules will melt into a liquid phase and a solid $\mathrm{MnO}$ phase. The reduction will occur on top of the cokebed until all the solid $\mathrm{MnO}$ is reduced. The slag will now be close to the liquidus composition. The slag is tapped close to the liquidus composition, which is linearly dependent on the basicity, in this article described as:

$$
B=\frac{\mathrm{CaO}+\mathrm{MgO}}{\mathrm{SiO}_{2}+\mathrm{Al}_{2} \mathrm{O}_{3}} .
$$

\section{OPEN ACCESS}

This article is distributed under the terms of the Creative Commons Attribution 4.0 International License (http://creativecommons.org/licenses/by/4.0/), which permits unrestricted use, distribution, and reproduction in any medium, provided you give appropriate credit to the original author(s) and the source, provide a link to the Creative Commons license, and indicate if changes were made.

\section{REFERENCES}

1. M. Tangstad, E. Ringdalen, E. Manilla, and D. Davila, TMS 2016 (Nashville, TN, 2016).

2. J.E. Davidsen, Summerjob-Report NTNU (Trondheim, Norway, 2009).

3. T. Brynjulfsen (Ph.D. Dissertation, NTNU, Norway, 2013).

4. E. Ringdalen, M. Tangstad, and T. Brynjulfsen, Infacon XIV (Kiev, Ukraine, 2015).

5. A. Muan and E.F. Osborne, Phase Equilibria Among Oxides in Steelmaking (Boston, MA: Addison-Wesley, 1965), p. 126.

6. S. Olsen, M. Tangstad, and T. Lindstad, Production of Manganese Ferroalloys (Norway: Tapir Forlag, 2007), pp. 159-162. 